\title{
SMART DATA FOR SMART CITY MORPHOLOGY: THE CASE OF MERIDIA NEIGHBORHOOD IN NICE, FRANCE
}

\author{
M. Caglioni ${ }^{1,}{ }^{*}$, G. Fusco ${ }^{1}$, A. Venerandi ${ }^{1}$ \\ ${ }^{1}$ Université Côte d'Azur, CNRS, ESPACE, Nice, France - (caglioni, fusco, venerandi)@univ-cotedazur.fr
}

Commission IV

KEY WORDS: Urban Forms, Morphometrics, Smart City, Neighborhood Comparison, 3D City Model.

\begin{abstract}
:
Nowadays, cities have to withstand multiple challenges such as climate change, increasing urban population, economic cycles, health crises, traffic congestion, rising levels of energy consumption and citizens' expectations. Recently, the smart city has been proposed as a model to face such challenges. Underneath its digital skin, which provides ubiquitous high-tech solutions, the smart city is often presented in continuity with the traditional city, while getting inspired by the modernist or international paradigm (free standing towers, high density development and functional zoning). Is this actually the case? To understand the features of urban form of new smart developments and how these relate to existing approaches in city planning, we propose a quantitative methodology to compare features of multiple city areas, which is based on the computation of a set of 3D morphometrics of the urban environment, and descriptive statistics for each metric. We applied this methodology to compare Nice Meridia, a French example of smart city development, with a traditional neighbourhood, located in the same city. Outcomes show that the smart city neighbourhood shares some morphological aspects with the traditional city, but differs significantly in other respects, showing the interest of quantitative 3D metrics.
\end{abstract}

\section{INTRODUCTION}

\subsection{Smart City}

The "Smart City" concept received an increasing attention in urban planning and governance in the last two decades: it is a response to recent urban challenges, such as the rapid expansion of urban population, traffic congestion, global energy consumption and greenhouse gas emissions, economic competitiveness and rising expectations of citizens (Washburn and Sindhu, 2010).

In geography and urban planning, the term "smart" refers more to the concept of intelligent growth (Batty et al., 2012), which implies greater urban efficiency, thanks to the coordination between conservation and economic development, optimizing resources and improving the life quality of citizens.

At the same time, we are talking about a city that exploits new opportunities such as technological advances in information and communication field (Lee et al., 2013). However, certain experts have doubts about Smart City initiatives, presenting them as simply celebrating labels for cities (Hollands, 2008), or artefacts of the information and communication industry (Anthopoulos, 2017).

What is missing, in today planning debate, is an accurate reflection on the design model underneath this digital skin (Rabari and Storper, 2014) of smart cities. They are often presented in continuity with the traditional city, while getting inspired by the modernist or international paradigm (free standing towers and functional zoning) (Venerandi et al., 2020). The present paper intends to investigate the forms of the smart city further, through set of 3D morphometrics.

\subsection{Paper aims}

New smart city projects worldwide tend to reconcile goals of ecological sustainability and economic development by proposing higher urban densities, abundant greenery and ubiquitous high-tech solutions (sensors, networks, data-driven apps, smart buildings). What is sought for in terms of urban form is instead vaguely defined in line with the compact city paradigm. Venerandi et al. (2020) showed that the physical form of the smart city is measurable and that claims of similarity with traditional forms can be assessed. Their work used a set of 2D morphometrics to compare Nice Meridia, with both $19^{\text {th }}$ century urban developments and the modernist suburban techno park of Sophia-Antipolis. Although this work shed more light on the underlying urban form of the smart city Nice Meridia, it overlooked aspects that can only be assessed through a 3D approach. In this context, the need for advanced geo-computational methods and models for 3D spatial modeling in support of urban design and decision-making is particularly evident. Most of the recent works in 3D applications are intended for visualization and presentation purposes only. However, novel techniques (e.g., 3D Urban Geographical Information Systems, 3D city spatial data models, 3D topological relationships, height-related and façade-related characteristics) are now becoming very relevant as analysis tools too (Zlatanova and Gruber, 1998; Held et al., 2004; Kolbe and Plümer, 2005).

The goal of this paper is thus to show how a $3 \mathrm{D}$ city model can be used to assess the form of the smart city. Following Venerandi et al. (2020), the comparison of smart city projects and traditional urban forms is particularly intriguing. The manifest similarities go often hand in hand with less evident and still fundamental differences. We thus want to ascertain how the understanding of these similarities and differences can be improved through 3D morphometric analysis. The focus of the 
analysis will be the 3D perception of the neighborhood from the public space, more than the $3 \mathrm{D}$ characterization of individual buildings, in line with the most recent developments in urban morphology (Hermosilla et al., 2014; Leduc and Chauvat, 2015; Araldi and Fusco, 2019).

\section{THE CASE STUDY}

\subsection{Nice Meridia neighborhood}

Meridia is an emblematic example of Smart City in France. It is a new urban development located in the westernmost section of the city of Nice, near the Var river. This area, which covers 24 hectares with a building capacity of 370,000 square meters, is the object of an Operation of National Interest, Opération d'Intérêt National (OIN), in French, carried out by the French Government through a local Planning and Development Authority (EPA), which involves several stakeholders. The EPA Plaine du Var announced that, by 2030, the area will host around 2,500 collective dwellings and 5,000 jobs in different activities, such as private companies, retailers, services, private and public research laboratories, and a new university campus. The general contractor Devillers \& Associated is in charge to elaborate the masterplan, which includes building volumes and functions, and ensures the necessary architectural and landscape coordination.

Devillers' masterplan is supposedly designed to incorporate concepts of sustainability, climate resilience, and smart city. For example, a relevant portion of the neighborhood surface has been left unpaved to facilitate the drainage of stormwater towards the underground aquifers and nearby riverbed. Furthermore, several public buildings are planned to be equipped with photovoltaic panels to reduce energy consumption. For what concerns features of the smart city, the new neighborhood is planned to rely on a computerized system to manage the geothermal power used to heat and cool the housing units, offer a network of charge points for electric vehicles and sensors to monitor pollution levels (EPA Plaine du Var, 2013).

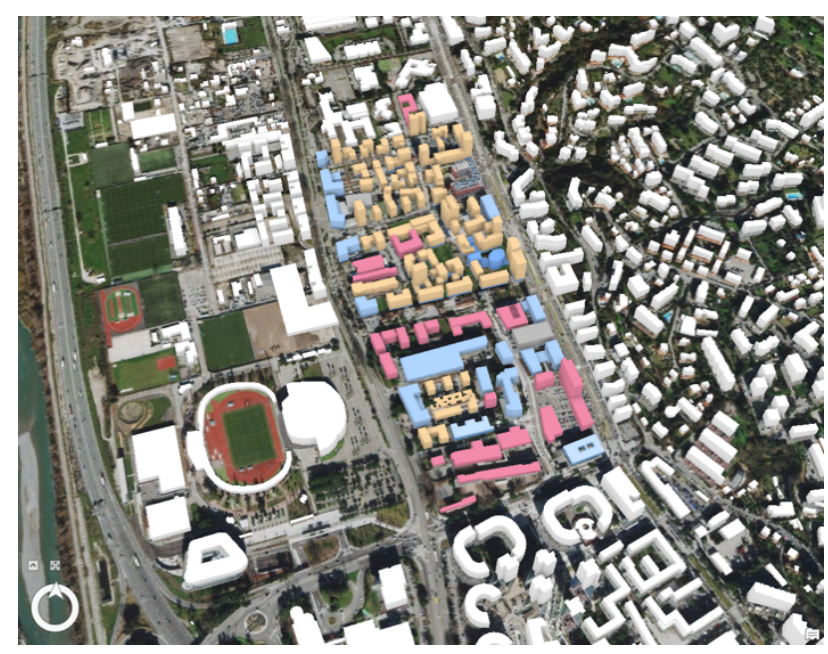

Figure 1. Nice Meridia masterplan. CityEngine model.

In figure 1, we show the masterplan by Devillers (version 2018) of Nice Meridia neighborhood for 2030, built by the authors as 3D parametric model at floor level in the ESRI platform CityEngine. Residential buildings are in yellow, offices in light blue, university campus and learning centers are in pink, hotels and shops are in blue, while parking facilities are in grey. White represents existing buildings outside the study area.

\section{METHODOLOGY}

The dataset to carry out the analysis presented in this paper was provided by the local Planning and Development Authority (EPA) and contained 2D geometric information (in dwg Autodesk AutoCAD format) about subdivisions, parcels, roads, sidewalks, and building footprints. It corresponds to the Devillers' masterplan updated to 2018. The masterplan is flexible and constantly updated whenever new land is bought by the public agency and tender outcomes are known. The end of the development is planned for 2030 .

ESRI CityEngine was then used to rapidly generate 3D models of the case studies under examination from the 2D information mentioned above, in a parametric way. More specifically, CityEngine makes it possible to produce 3D buildings or other objects, at any Level of Detail (LoD), thanks to geometrical construction rules, which makes it possible to interact with their parameters. These rules are written in Computer Generated Architecture (CGA) language, which is a formal programming language that allows to build any $3 \mathrm{D}$ object in the study area (buildings, streets, parks, urban furniture, etc.) and calculate 3D Key Performance Indicators (KPI). These can then be visualized in a graphic dashboard or directly in the $3 \mathrm{D}$ models and can provide useful information for scenario modelling. CityEngine also permits to compute measures of street network centralities (e.g., local and global Betweenness, Closeness, and Reach) (Porta et al., 2006) and 3D visibility analyses (e.g., Viewshed, Dome $360^{\circ}$ and View Corridor).

To better understand the structure of the 3D model generated by the construction rules and the composition of the geographic objects represented at the different levels of detail (LoD), an example of ontology (taxonomy) of all the objects of the model of Nice Meridia is presented in figure 2.

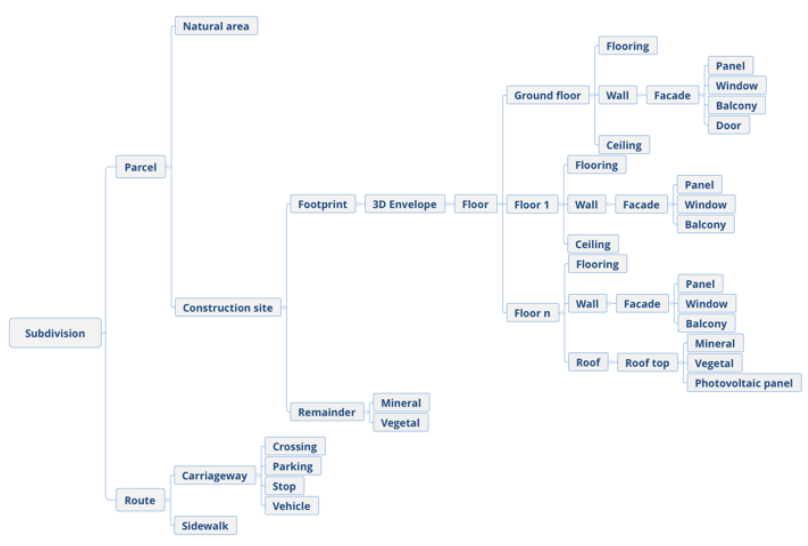

Figure 2. 3D semantically enriched model of Nice Meridia, in CityEngine.

The starting point for the construction of the $3 \mathrm{D}$ model is the subdivision, a 2D surface ready to be built. The subdivision is made of two separate objects: roads and parcels. The latter represent the subdivisions of a two-dimensional surface surrounded by roads. Each parcel can represent a natural or built-up area, which could contain, for example, the footprint of 
a building, a mineralized area, and a garden. The CGA rules then use this information to construct the $3 \mathrm{D}$ envelopes of the buildings and divides these envelopes into floors. These have the same structure, except the ground floor and last floor. The former, in fact, is usually higher than the others, offers commercial activities, and has one or more entrances. The latter is topped by the roof. The walls of each floor are characterized by an oriented facade with architectural elements (windows, balconies, awnings, etc.) generated in 3D and adjustable thanks to the parameters of the CGA rules. In the same way, the CGA rules make it possible to manage the shape and the typology of the roof, allowing to choose a mineral (waterproof) cover, green cover, or photovoltaic panels.

The resulting 3D model, made by multipatch objects, was then exported in a 3DCityDB geodatabase, compatible with the CityGML format (www.3dcitydb.org), and subsequently imported in ESRI ArcGIS Pro. This software was then used to compute the $3 \mathrm{D}$ morphometrics for the two neighborhoods under examination. More specifically, these measures were based on sun shadows and skylines (3D objects created with the 3D Analyst Toolbox of ESRI ArcGIS Pro version 2.5). The formers are modeled as closed multipatches, extruding the buildings in the direction of the sunlight, for given date and time. Multiple shadow volumes were then generated to calculate the daily sun shadow frequency over the unbuilt areas of the two neighborhoods under examination. For what concerns the skyline, it is a closed 3D polyline that separates the buildings or the land from the sky, starting from a given observation point. This information was used to compute the distributions of the vertical and horizontal angles of the skyline vertices, the distributions of the distances between the observation points and the skyline vertices.

In the following sections, we present the analyses based on this data for the two study areas (Nice Meridia and Hotel des Postes) and compare their respective values of 3D morphometrics.

\section{ANALYSES AND RESULTS}

To understand the features of urban form of new smart developments and how these relate to existing approaches in city planning, we propose a quantitative methodology to compare features of multiple city areas, which is based on computation of a set of 3D morphometrics of the urban environment and descriptive statistics for each metric. We applied this methodology to compare the urban forms of Nice Meridia (Figure 1) with those of Hotel des Postes (Figure 3), a traditional neighbourhood located in the same city. Hotel des Postes has already been used as a benchmark by Venerandi et al. (2020) for the comparative 2D-assessment of the Meridia project. This neighbourhood is today part of the city-centre of Nice and was planned in the mid- $19^{\text {th }}$ century by the Consiglio d'Ornato, a pre-modern planning body (Graff 2000). It is characterised by perimeter blocks lying on an urban grid that follows the bend of a nearby river (the Paillon river), several public squares, a homogeneous $15-20 \mathrm{~m}$ building height, and a relatively high building coverage.

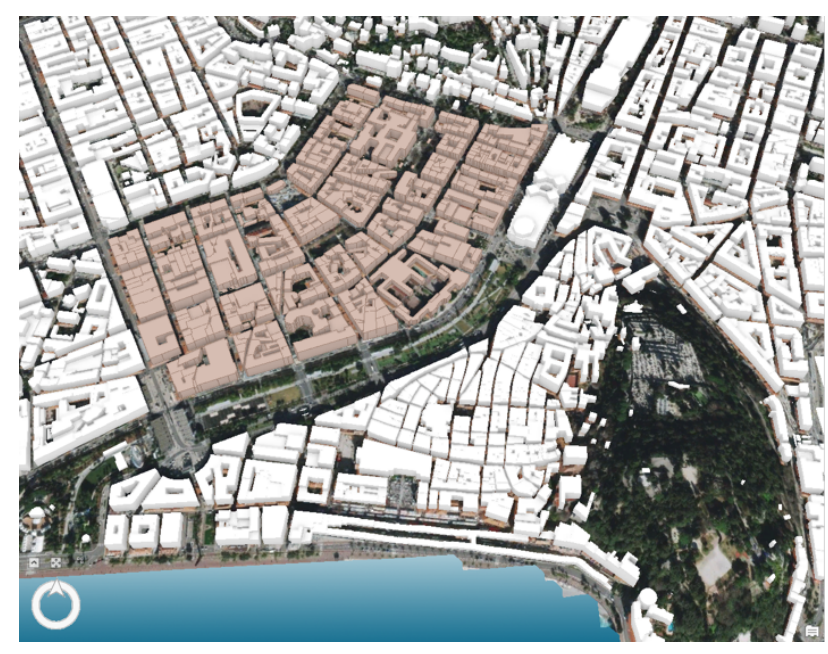

Figure 3. Hotel des Postes neighborhood, Nice, France.

\subsection{Daily Sun Shadow Frequency}

It is common sense and a well-established practice since the $19^{\text {th }}$ century to design buildings and urban forms by taking into account sunlight to increase the amount of light inside dwellings, at the street level, and, more recently, to optimize the solar panel energy production. However, in the traditional Mediterranean cities, where the sun shines most of the year, direct sunlight during the day was strongly avoided. Indeed, they were designed to allow pedestrians to walk around the neighborhood while being protected by the shadows of buildings or by green canopies (Hakim, 2014). In order to quantify the amount of shadow in the open spaces, during a whole day, we decided to the following shadow metric.

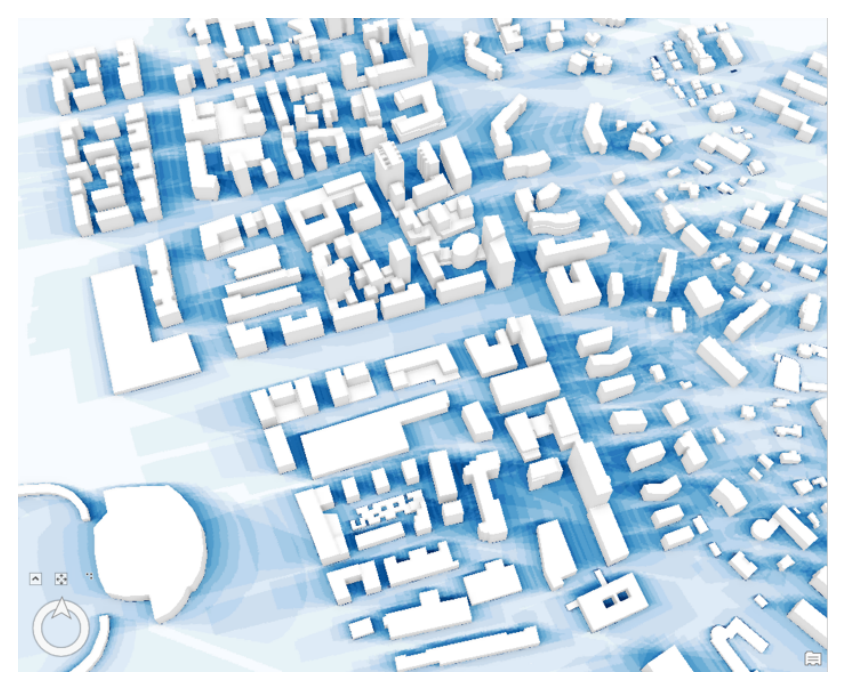

Figure 4. Nice Meridia daily sun shadow frequency.

The daily sun shadow metric count for each pixel (1m x 1m) of non-built-up area how many hours of shadow we have during a whole day. For calculation purposes, we chose the day of the summer solstice (June $20^{\text {th }}, 2020$ from 6 am to $8 \mathrm{pm}$ ), when there is the most sunlight of the year. The metric calculates the number of times a fixed position on the ground has its direct sight line to the sun obstructed by buildings (multi-patch features) or by the digital terrain model. 


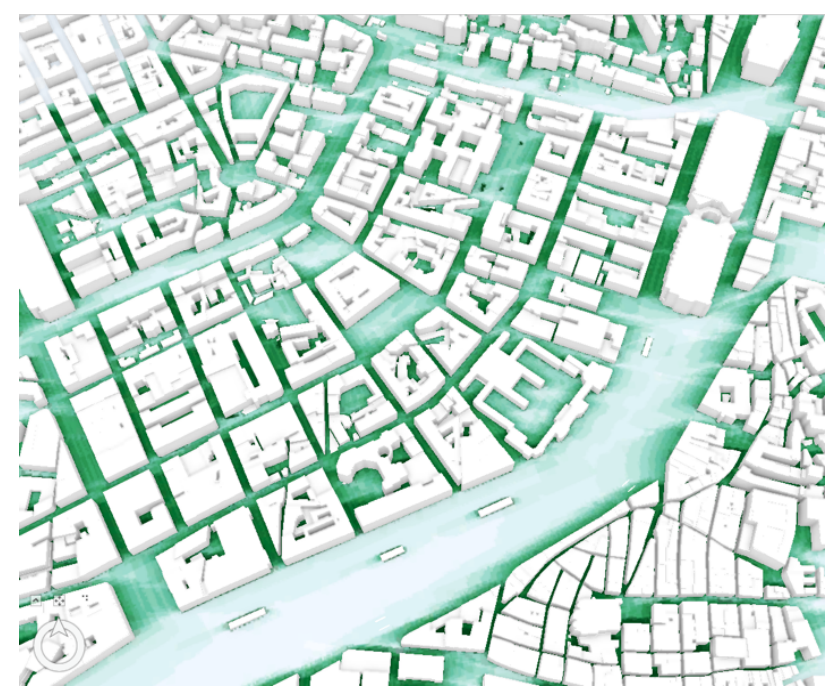

Figure 5. Hotel des Postes daily sun shadow frequency.

In order to avoid edge effects, this analysis is performed considering a $500 \mathrm{~m}$ buffer around the perimeter of Nice Meridia and Hotel des Postes. The frequency plot of the daily sun shadows (Figure 6) shows only the values inherent to the blocks of the study area (Figure 4 and 5).

The shadow frequency plot in figure 6 shows some fundamental differences between Nice Meridia and Hotel des Postes neighborhoods. Meridia (in blue line) presents much more non built-up areas, with few hours of shadow (left side of the plot). This means that in Meridia we have more public and private spaces that are in the sun for most of the day. On the contrary, Hotel des Postes shows a pick around 11 hours of shadows, which means that non built-up spaces are quite often protected from the sunlight. Indeed, $19^{\text {th }}$ century Hotel des Postes has been designed with 10 to $15 \mathrm{~m}$-wide streets and 15 to $20 \mathrm{~m}$-tall buildings. Although representing a more modern solution in comparison to the narrow alleys of the old city, this layout assures a protection against the sun and keeps the temperatures as low as possible during the day.

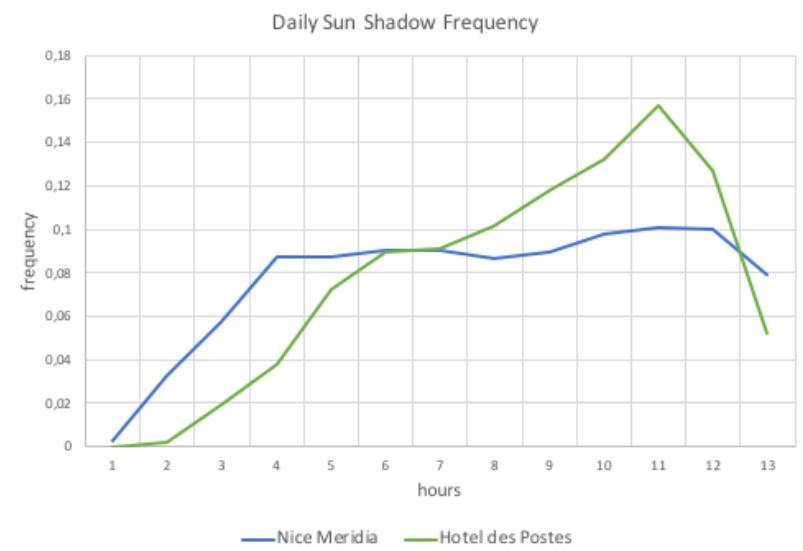

Figure 6 . Nice Meridia daily sun shadow frequency plot.

Figure 6 also shows that Nice Meridia has more space without sunlight in the range 1 to 5 hours and a uniform distribution in the range 4 to 13 , which signifies a better equilibrium between sunny and shadowy areas in the neighborhood. In Hotel des Postes, the number of zones with shadow increase linearly with hours until the pick of 11 hours, which attests an accumulation of shadow during the day far from midday (when we have no shadow in this area).

In the following sections, we will discuss further 3D metrics that are more related to the perception of city users, that is how an observer sees the three-dimensional shapes of the neighborhood.

\subsection{Skylines and Skyline Barriers}

A skyline is a unique fingerprint of a city. Besides the qualitative evaluation of its aesthetic component, several authors proposed more analytical approaches based on 3D spatial information (Guney et al., 2014). We propose here a quantitative analysis of multiple skylines of the study areas, using 3D analyst tool of ESRI ArcGIS Pro (Shephard, 2010).

The Skyline is a closed 3D polyline, which represent the line separating the sky from the vertical surfaces (building façades) or the relief (digital elevation model) surrounding an observation point. If the observer can see all the way to the edge of the surface in a given direction, then the vertex is generated at the point where the line of sight reaches the edge of the surface. The horizon line is generated by casting a line of sight from the observer, covering the azimuth range. A line of sight is checked after each azimuth increment (1 degree) from 0 to 360 degrees. A maximum horizon radius is provided, so the vertex will still be along the line of sight but no further from the observation point than $1,000 \mathrm{~m}$. A skyline example is presented in figure 7.

The Skyline Barrier is a height control surface generated from skylines. They are multi-patch surfaces defined between the observation point and the skylines associated with this point. In order to use some 3D solid operations such as 3D union and 3D intersect, we generated the volume between the skyline barrier and the ground as showed in figure 7 , in transparent light blue color.

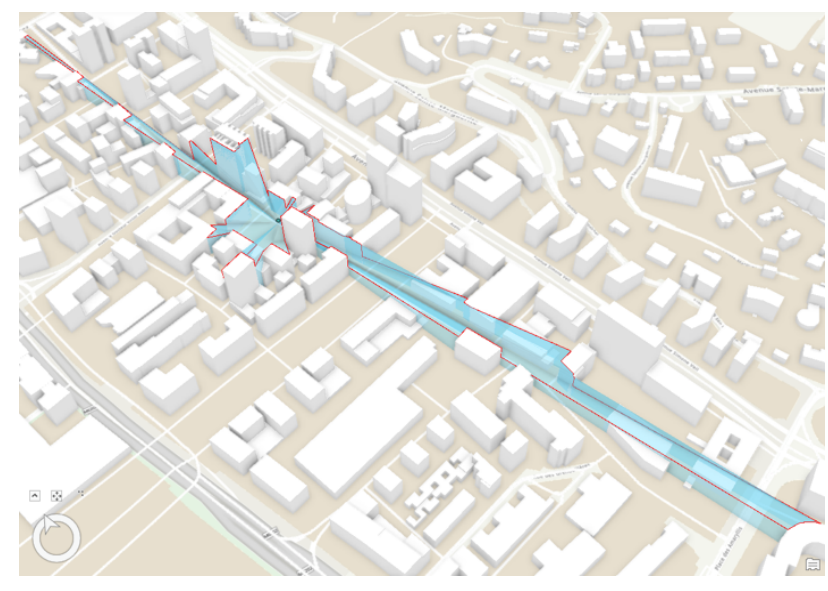

Figure 7. Example of skyline and skyline barrier from an observation point. The red lines correspond to the skyline.

Skylines and Skyline Barriers are calculated starting from multiple observation points. These points are placed on the street network every 10 meters, starting from each crossing, at 1.75 meters of height from the ground, to simulate a pedestrian walking on the street. 
4.2.1 Skyline Horizontal Angle: Every skyline is a complex polyline, made by hundreds of vertices in three dimensions. In order to describe this composite shape, we chose to consider the value of the horizontal angle (Azimuth) of the maximum 3D distance between the observer and the vertices of the skyline. The Azimuth is the angle (in degrees) formed between the north and the direction of the 3D maximum distance.

The 360-degree radial scatterplot of the skyline azimuth for Nice Meridia is compared with the scatterplot of Hotel des Postes in figure 8.

A main difference between Meridia and Hotel des Postes is the dispersion of the points around the observer in the center. Each point represents the farthest skyline vertex from the observer, i.e. the maximum depth of his/her field of view. For Nice Meridia neighborhood this distribution is concentrated around between 500 and 1,000 meters for the maximum 3D distance. Conversely, Hotel des Postes shows a larger variety of skyline openings, from 200 meters to 1,700 meters from the observer. Following the principles of the Townscape (Cullen, 1961), this variety in directions and in the depth of the field of view contributes to more picturesque serial visions along the streets of this traditional neighborhood.

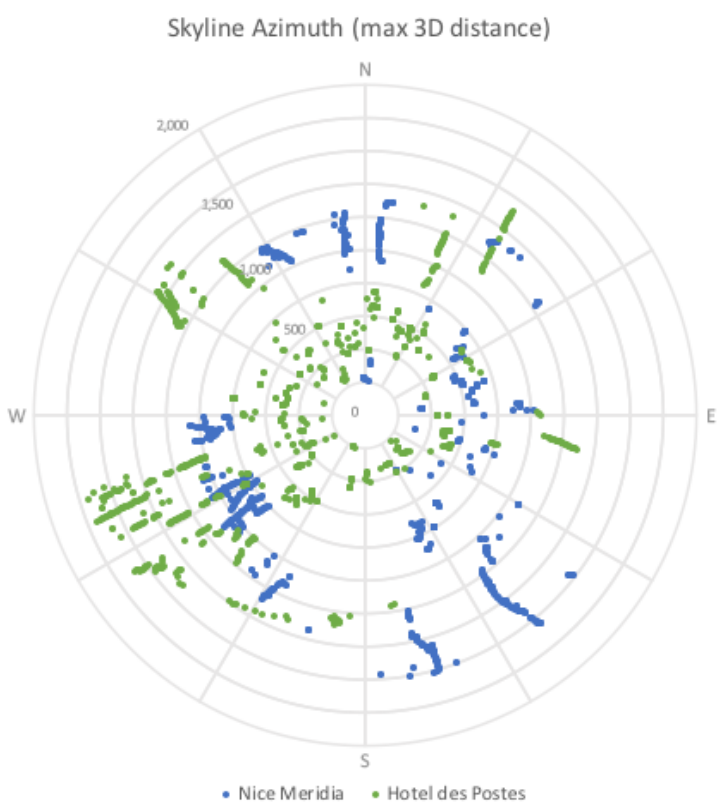

Figure 8. Skyline Azimuth radial scatterplot.

The scatterplot in figure 8 can be summarized by the frequency plot presented in figure 9, where we can observe the more recurrent orientation of the farthest vertex of each skyline.

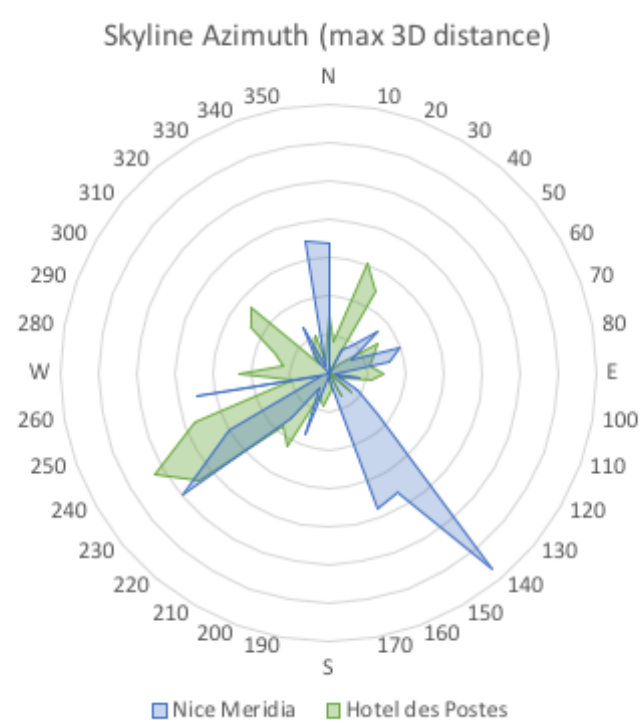

Figure 9. Skyline Azimuth radial frequency plot.

As we can observe in the figure 9, most skylines in Nice Meridia follow the main perpendicular directions of the neighborhood: South-South-Est (SSE) and West-South-West (WSW), with large visual openings towards a nearby housing project in the South and the Var river (which is nevertheless out of sight from the streets in Meridia) in the West. Other directions are immediately occluded by adjacent high-rise buildings. Nice Meridia strictly respects an orthogonal grid. The openings to the North and East point to the hills. We furthermore observe that the opening between $230^{\circ}$ and $260^{\circ}$ is not continuous due to the sightline occlusion made by the concert hall Palais Nikaia.

As it can be inferred from the structure of the blocks (Figure 3), the skyline azimuth plot for Hotel des Postes shows the presence of at least two adaptive grids orthogonal to the Paillon river. The greatest visual opening in West-South-West direction points to the sea.

4.2.2 Skyline Vertical Angle: Each Skyline can be described also by the value of its vertical angle. This is the angle formed between the ground and the direction resulting from the straight lines joining the observer and each skyline vertex. The vertical angle is $0^{\circ}$ when the observer sightline is parallel to the ground and $90^{\circ}$ when it is perpendicular to the ground, in zenith direction

Vertical angles formed with the buildings bordering public streets have been carefully regulated by urban planning since the $19^{\text {th }}$ century through width-to-height ratios, with maximum values ranging between $60^{\circ}$ and $75^{\circ}$ when calculated from the street centerline (Talen, 2012). As we did for the azimuth, we did not calculate the mean value of all vertical angles of each skyline, but we considered the vertical angle of the closest vertex to the observer within a limit of 50 meters. The results are the two multimodal distributions presented in figure 10 . 


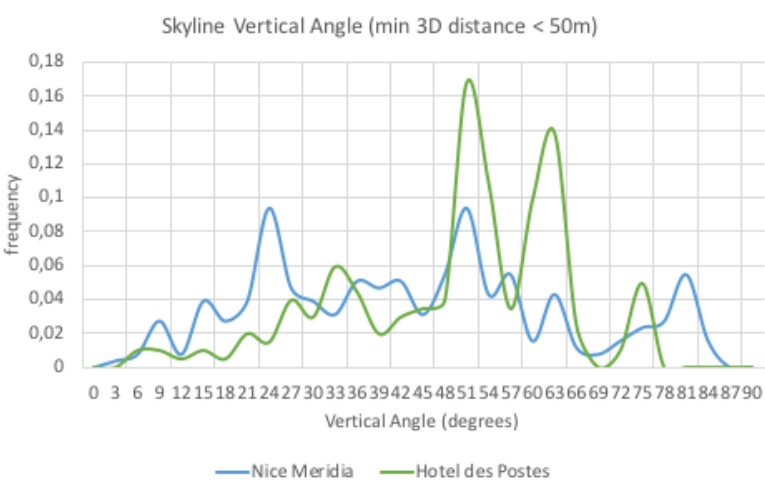

Figure 10. Skyline vertical angle plot.

Nice Meridia shows a wider distribution of values, as well as higher and lower peaks of vertical angles than Hotel des Postes. This is due to the variety of building heights, the presence of some high-rise buildings and of setbacks of different depth in front of many buildings. On the contrary, Hotel des Postes shows the highest frequency for the vertical angles in the range $50^{\circ}$ to $65^{\circ}$, with a smaller peak at $75^{\circ}$. This is essentially due to the standard use of traditional width-to-height rules around public streets, with widths varying between 10 and $15 \mathrm{~m}$, and heights between 15 and $20 \mathrm{~m}$ on block perimeters.

4.2.3 Skyline 3D Distance: 3D or slope distance is the mean of the Euclidean distances between the observer and the vertices of the skyline. If the buildings are absent, the horizon distance is taken with a limit of 1,000 meters around the observer, in this case $3 \mathrm{D}$ and $2 \mathrm{D}$ distances will be the same.

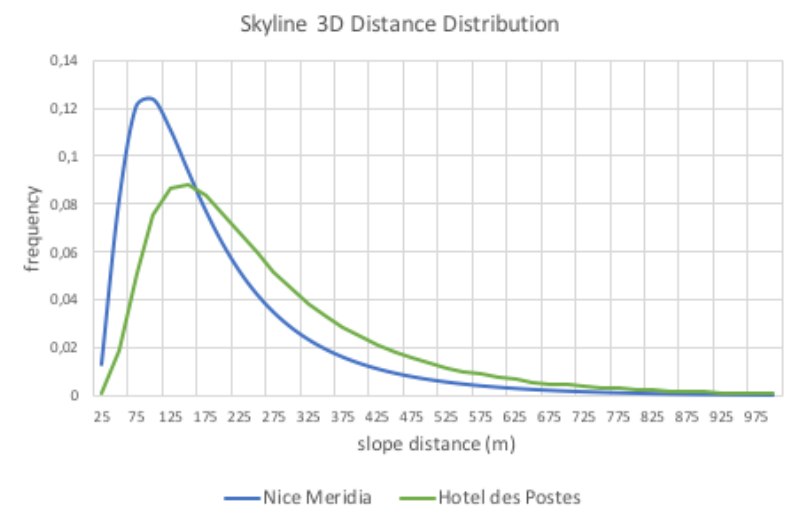

Figure 11. Skyline 3D distance plot.

It seems surprising in Figure 11 that the mean 3D distance for Nice Meridia (186.2 meters) is shorter than the one for Hotel des Postes (257.6 meters). Indeed, in Meridia the skyline never reaches the limit of 1,000 meters since, in this range, the sight is always obstructed by buildings. On the contrary, in the south part of Hotel des Postes, it is possible to see the sea and the line of sight can be extended further.

\section{CONCLUSIONS}

The smart city has been proposed as a solution for the challenges that our cities are currently facing. However, while a strong emphasis has been put on technological aspects, the urban model underlying the design of the smart city is not clear.
In this paper, we shed light on this topic by means of a comparative analysis between a smart city development (Nice Meridia) and a traditional neighborhood (Hotel des Postes), thorough several 3D morphometrics. Outcomes show that the two neighborhoods diverge substantially. For what concerns hours of sunlight, Meridia seems more aligned with modernist standards as it tends to have more sunlight in open spaces. However, this is not a desirable feature in the Mediterranean area. Meridia offers far fewer openings towards landscape elements than Hotel des Postes. Furthermore, the lengths of such openings tend to be uniform while, in the latter, these are much more diverse. Again, Meridia seems more similar to a grid shaped modernist scheme than to a more organic traditional urban form. Above all, both neighborhoods offer a certain variety of views to the observer walking on its public streets. However, the variety in Meridia derives from the intrinsic variety of building heights and setbacks and is mainly revealed on the vertical angles of observation. On the contrary, the variety in the traditional city is given by the coordination between building frontages, streets and openings towards the landscape, and is revealed in the horizontal angles and in the depths of the field of view. Smarter buildings seem to interact less among them and with the streets serving them than more traditional ones, at least from a visual point of view.

As further development of this work, the authors intend to take advantages of the fully 3D city model built for Nice Meridia, using the information at floor level on building usages and urban functions. Indeed, the skyline barriers used in this work can intersect, in the 3D space, vertical planes such as retail façades or horizontal surfaces such as gardens and parks. The estimation of commercial or green surfaces visible by pedestrians could constitute a proxy for measuring the intelligibility of urban space in smart city developments, but also in other case studies.

\section{ACKNOWLEDGEMENTS}

This work is part of the Trans-Metro-Med research project and has been supported by the French government, through the UCA JEDI Investments in the Future program managed by the National Research Agency (ANR) with the reference number ANR-15-IDEX-0.

\section{REFERENCES}

Anthopoulos L.G. (2017) Understanding Smart Cities: A Tool for Smart Government or an Industrial Trick? Public Administration and Information Technology 22, Springer International Publishing AG.

Araldi A., Fusco G. (2019) From the street to the metropolitan region: Pedestrian perspective in urban fabric analysis. Environmental and Planning B: Urban Analytics and City Science, 46(7), 1243-1263.

Batty M., Axhausen K.W., Giannotti F., Pozdnoukhov A., Bazzani A., Wachowicz M., Ouzounis G., Portugali Y. (2012). Smart cities of the future. European Physical Journal Special Topics, 214, pp. 481-518.

Cullen G. (1961) The Concise Townscape. Architectural Press, Oxford. 
EPA Plaine du Var (2013) Nice Meridia: An urban technopolis for an intense city. Press release. Available at: http://www.ecovallee-plaineduvar.fr/sites/default/files/fichiers/ dp_nicemeridia_2013_gb_v_0.pdf

Fusco G., Araldi A. (2017) The Nine Forms of the French Riviera: Classifying Urban Fabrics from the Pedestrian Perspective. In D. Urios, J. Colomer et A. Portalés (Eds.), 24th ISUF International Conference: City and territory in the Globalization Age, Conference Proceedings, Editorial Universitat Politècnica de València, pp. 1313-1325.

Graff P. (2000) L'exception Urbaine. Nice : de la Renaissance au Consiglio d'Ornato. Marseille, Parenthèses.

Guney C., Girginkaya S.A., Cagdas G., Yavuz S. (2012) Tailoring a geomodel for analyzing an urban skyline. In Landscape and Urban Planning, Elsevier, Vol. 105, Issues 1-2, pp. 160-173.

Hakim B. (2014) Mediterranean Urbanism. Berlin, Springer.

Held G., Abdul-Rahman A., Zlatanova S. (2004) Web 3D GIS for Urban Environments. Proceedings of the International Symposium and Exhibition on Geoinformation (ISG2004) Kuala Lumpur, Malaysia.

Hermosilla T. et al. (2014) Using street-based metrics to characterize urban typologies. Computer, Environment and Urban Systems 44, pp. 68-79.

Hollands R.G. (2008) Will the real smart city please stand up? City, Vol. 12, N. 3.

Kolbe T.H., Plümer L (2005) CityGML - Interoperable access to 3D city models. In Oosterom, Zlatanova, Fendel (Eds.) Proceedings of the International Symposium on Geoinformation for Disaster Management, Delft, Springer Verlag

Leduc T., Chauvat G. (2015) Etude comparée de quatre indicateurs qualifiant le champ visuel d'un piéton en milieu urbain. Revue Internationale de Geomatique 25(1), pp. 75-98.

Lee J.H., Phaal R., Lee S.-H. (2013) An integrated servicedevice-technology roadmap for smart city development. Technological Forecasting and Social Change 80, pp. 286-306.

Porta S., Crucitti P., Latora V. (2006) The network analysis of urban streets: a primal approach. Environment and Planning B: Planning and Design, 33(5), 705-725.

Rabari C., Storper M. (2014) The digital skin of cities: Urban theory and research in the age of the sensored and metered city, ubiquitous computing and big data. Cambridge Journal of Regions, Economy and Society, 8, pp. 27-42.

Shephard N. (2010) Using 3D volumetric analysis techniques in ArcGIS 10. In Answering Real-World Questions. ESRI, ArcUser, Fall 2010.

Talen E. (2012) City Rules. How Regulations Affect Urban Form. Island Press, Washington.

Venerandi A., Fusco G., Caglioni M. (submitted 2020) The form of the smart city. A comparison with previous design paradigms. Urban Design International journal, Springer.
Washburn D., Sindhu U. (2010) Helping CIOs Understand "Smart City" Initiatives. Forrester Research.

Zlatanova S., Gruber M. (1998) 3D Urban GIS on the Web: Data Structuring and Visualisation. In D. Fritsch, M. Englich \& M. Sester (Eds.) 'IAPRS', Vol. 32/4, ISPRS Commission IV Symposium on GIS - Between Visions and Applications, Stuttgart, Germany. 